\title{
Экологически безопасная продукция перца сладкого в весенних теплицах
}

\begin{abstract}
В.В. Огнев, Т.В. Чернова, А.Н. Костенко, Е.Н. Габибова, В.К. Мухортова, С.С. Авдеенко

Представлена характеристика гибридов перца сладкого для весенних теплиц и технология их возделывания с использованием сидератов и биологических средств защиты растений позволяющая получать экологически безопасную продукцию.
\end{abstract}

Ключевые слова: перец сладкий, гибрид, весенние теплицы, биологическая защита, сидераты.

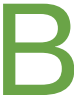
последние годы перец сладкий приобретает все большую популярность среди овощных культур по всей России. Способствует этому постоянное присутствие свежих плодов на прилавках супермаркетов и изменение приоритетов в питании населения в направлении включения в рацион новых продуктов, обладающих богатым химическим составом и биологической ценностью [1]. Перец сладкий ценится как поливитаминный концентрат с выраженной антиоксидантной активностью, наиболее подходящий для функционального питания. Среди других овощей он выделяется как премикс, способный улучшать питательную ценность любых блюд и консервов с его добавками [2].

Сложности с круглогодичным выращиванием перца сладкого в России связаны с низкой популярностью культуры в защищенном грунте и сильно выраженной сезонностью производства в открытом грунте. Повышенная теплотребовательность культуры ограничивает ареал возделывания в открытом грунте главным образом южными регионами [3]. В защищенном грунте основные препятствия - относительно низкая урожайность в сравнении с томатом и огурцом, отсутствие прогрессивных технологий выращивания в защищенном и утепленном грунте.

Постепенное увеличение площадей зимних теплиц будет способствовать расширению ассортимента возделываемых в них культур [4]. Однако не в полной мере задействованы возможности весенних теплиц и утепленного грунта. Значительные площади этих видов защищенного грунта позволяют расширить ассортимент возделываемого здесь набора овощных культур, тем более что по огурцу и томату наблюдается относительное перепроизводство в раннем сегменте. Перец и баклажан - первые кандидаты для обновления ассортимента культур в весенних теплицах [5]

Выращивание перца сладкого в весенних теплицах требует соответствующего научного сопровождения, которое должно обеспечивать создание специального сортимента и разработку современных технологий по получению высоких урожаев экологически безопасной продукции. При этом сортимент должен обладать комплексом признаков, которые в наибольшей степени присущи гетерозисным гибридам, а не свободноопыляющимся сортам [6].

Цель исследований: создание конкурентоспособного сортимента перца сладкого для весенних теплиц на юге России и усовершенствование технологии его возделывания на основе биологизации технологического процесса.

Исследования проводили в 20102018годахнатерриторииОктябрьского сельского района Ростовской области в ФГБОУ ВО ДОНСКОЙ ГАУ и ООО ССЦ «Ростовский» Агрохолдинга «Поиск» в весенних теплицах при грунтовой культуре. В селекционном процессе использован собственный исходный материал и образцы мировой коллекции ВИР. При разработке элементов технологии изучали различные виды сидератов и биопрепаратов на фоне традиционной технологии с применением капельного оро- шения и фертигации. Основной метод исследований - лабораторно-полевой. Применяли общепринятые методики проведения учетов и наблюдений [7]. Культивационные сооружения представляли собой необогреваемые ангарные теплицы со светопрозрачным покрытием из сотового поликарбоната. Почвогрунты - естественные почвенные разности улучшенного состава за счет внесения разрыхлителей и повышенных доз органических удобрений. По механическому составу грунты относились к легкому суглинку. Содержание органического вещества свыше 37\%. Обеспеченность элементами питания - высокая, $\mathrm{pH}$ среды - 7,2. Перец сладкий выращивали в рассадной культуре с пикировкой и забегом 45 дней. Микроклимат поддерживали за счет проведения поливов и использования приточно-вытяжной вентиляции. Площадь питания растений - 70×25 см с подвязкой к опорам и формировкой типа «плодовая стена».

Создание сортимента перца сладкого для весенних теплиц потребовало изучения имеющегося исходного материала и привлечения в качестве доноров ценных признаков лучших сортов и гибридов из мировой коллекции ВИР, сортообразцов зарубежных селекционно-семеноводческих фирм. В результате изучения четко выявили общемировую тенденцию к переходу от возделывания свободноопыляющихся сортов к возделыванию гибридов первого поколения. Таким образом, в качестве основного тренда в селекции был выбран путь создания гетерозисных гибридов. Селекция на гетерозис предполагает получение линейного материала с комплексом хозяйственно ценных признаков и свойств, определение комбинационной способности полученных линий и отработку технологий получения гибридных семян с минимальными затратами.

В общей сложности было изучено свыше 500 сортов и гибридов различного эколого-географического проис- 
хождения. На их основе было создано более 30 линий с высокой комбинационной способностью. Наиболее высокий эффект гетерозиса и сочетание в одном генотипе ценных признаков отметили в комбинациях скрещивания, где в качестве родительских форм использовали собственный исходный материал и материал, полученный из образцов селекции компаний из Восточной и Западной Европы (Нидерландов, Венгрии, Сербии), а также из Китая. Наибольший интерес представляют полученные гибриды первого поколения с призмовидной и кубовидной формой плодов, сочетающие крупноплодность, толстостенность, привлекательную окраску с сильным перечным ароматом, высокой урожайностью и товарностью, устойчивостью к болезням увядания, альтернариозу и бактериозу. Среди наиболее перспективных следует отметить гибриды $F_{1}$ Илона, $F_{1}$ Премьер, $F_{1}$ Корнелия, $F_{1}$ Валентина и $F_{1}$ Альянс. Несколько сложнее оказалось создать гибриды с конусовидной формой плода. Самый продуктивный из гибридов с конусовидной формой плода $-F_{1}$ Байкал. Новые гибриды име-

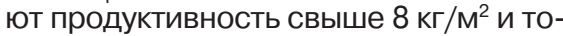
варность более $90 \%$. Однако в большинстве комбинаций гетерозис по величине урожайности не превышал 10-15\% по отношению к лучшему из родителей. Гибриды с низкой комбинационной способностью менее конкурентоспособны при выращивании в весенних теплицах. Здесь поиск ценных генотипов и создание на их основе линейного материала продолжаются.

При получении гибридных ceмян первых гибридов использован способ искусственной гибридизации с удалением пыльников в цвет-
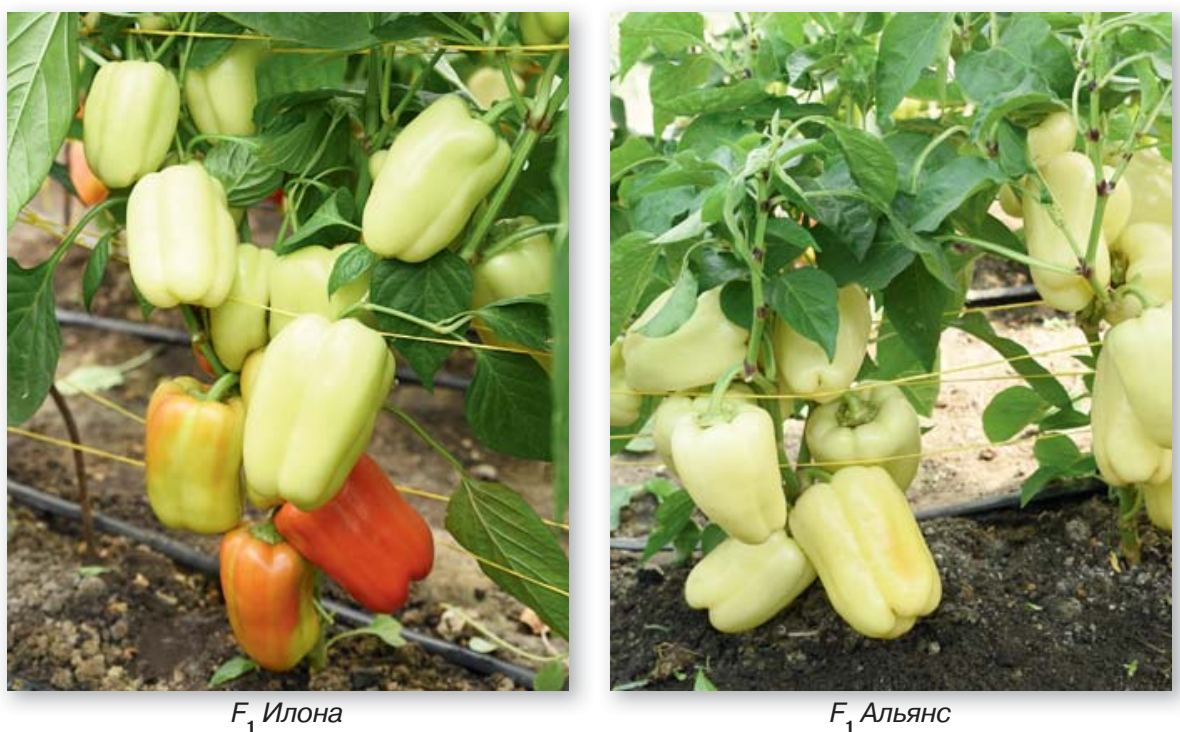

$F_{1}$ Альянс

ках женских линий. Трудоемкость проведения этой операции выдвинула необходимость использования явления мужской стерильности, исключающего кастрацию. Несколько гибридов получены на основе использования ЦМС. ЦМС ядерно-цитоплазматического типа позволяет получать относительно дешевые семена со 100\%-ной гибридностью. Однако процесс получения линий усложняется необходимостью создания генофонда стерильных линий и их фертильных аналогов - закрепителей стерильности, а также линий-восстановителей фертильности. Работы в этом направлении в ближайшее время позволят создать серию гетерозисных гибридов на стерильной основе с комплексом хозяйственно ценных признаков, первый из которых уже рекомендован к использованию под названием $\mathrm{F}_{1}$ Белогор.

В весенних теплицах выращивание перца сладкого сопряжено с рядом технологических особенностей. А поскольку продукцию перца используют преимущественно в свежем виде, в том числе для организации функционального питания и оздоровления населения, то на первое место выдвигаются проблемы, связанные с получением экологически безопасной продукции. Высокая степень химизации технологического процесса при бессменном выращивании на грунтах создает опасность загрязнения продукции. Монокультура не только вызывает почвоутомление и одностороннее истощение естественного плодородия грунтов, но и приводит к накоплению комплекса болезней и вредителей, для контроля которых до сих пор использовали только химические средства защиты растений.

Развитие индустрии биологической защиты и усовершенствование технологии выращивания перца сладкого в сочетании с освоением новых высокопродуктивных гибридов с генетической устойчивостью к болезням позволяет повысить доходность культуры и ее привлекательность для товаропроизводителей, а потребителям обеспечивает получение ценного экологически безопасного продукта питания.

Для предотвращения негативных последствий при бессменном возделывании перца в весенних теплицах нами разработана и прошла апробацию в тепличных хозяйствах усовершенствованная технология его производства, включающая применение биопрепаратов и выращивания сидеральных промежуточных культур.

Наиболее технологично включение в культурооборот наряду с перцем сладким таких промежуточных культур, как овес, ячмень, рожь и тритикале с добавлением бобового компонента или без него. В зависимости от продолжительности теплого периода после уборки перца сладкого подбирается конкретная промежуточная культура. При продолжительном периоде это яровые злаки: ячмень или овес, а при коротком - морозостойкие озимые злаки: рожь или тритикале. Злаки формируют большую биомассу, при разложении которой почва обогащается органическим веществом, снижается ее плотность, а развивающаяся при этом микрофлора является антагонистом многих возбудителей болезней. Микробы целлюлозоразрушители потребляют много азота, для восполнения недостатка которого после ска-

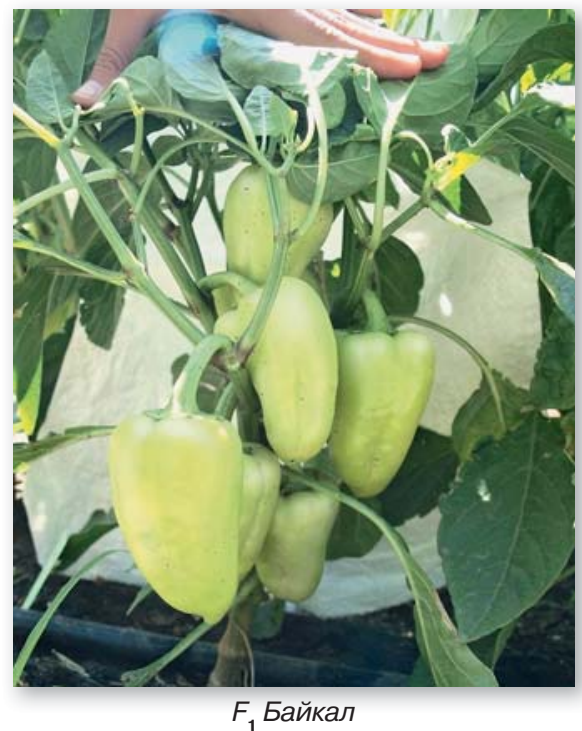

№1/2019 Картофель и овощи 
шивания в почву вносят дополнительное азотное удобрение в виде мочевины или аммиачной селитры. Хороший эффект дает обработка биомассы скошенных злаков культурами живых микроорганизмов с последующей их запашкой. Разложение растительных остатков лучше идет при положительных температурах и оптимальном увлажнении, что в теплицах обеспечить легче, чем в открытом грунте. Наиболее эффективными препаратами для разложения растительных остатков оказались Глиокладин, Стерня, Стернифаг, а из новинок Биокомплекс БТУ (биодеструктор). Менее эффективны препараты из группы ЭМ (Байкал, Восток). Для удешевления системы удобрений одновременно с запашкой сидератов вносят комплексные балластные удобрения типа нитромаммофоски в дозе 120 кг д.в. на 1 га. Через систему фертигации применяют безбалластные водорастворимые удобрения специальных марок (типа Акварин, Мастер, Полифид и т.п.), содержащие кроме основных элементов питания и микроэлементы, стимуляторы и регуляторы роста. До начала плодообразования важны прежде всего азот и фосфор, а в период налива плодов азот и калий. В период приживания сеянцев и рассады в составе удобрений нужны стимуляторы корнеобразования, а в период плодоношения - стимуляторы плодообразования и налива плодов. Подкормки проводят регулярно в течение вегетации в суммарной дозе 60 кг д.в. на 1 га. Предложенная система питания не приводит к накоплению нитратов в продукции, содержание которых укладывается в действующие санитарные нормы.

Защита растений в период вегетации основана на применении биопрепаратов. Против вредителей наиболее эффективен препарат Фитоверм, подавляющий клеща, тлю и ограничивающий численность трипса и белокрылки. Против различных видов совок лучшие результаты обеспечивают препараты Лепидоцид и Битоксибациллин. Для лучшего покрытия поверхности растений и контакта с вредителями опрыскивание должно проводиться с большим расходом рабочего раствора и с применением биоприлипателя Липосам. Несколько сложнее обеспечивается защита от болезней. От болезней увядания (фузариоз и вертициллез) должно быть сочетание генетической устойчивости сорта и внесения в процессе приготовления субстрата и через капельные системы препаратов Глиокладин,
Алирин-Б. Против листовых и плодовых инфекций можно использовать эти же препараты, а также Гамаир и Микозар. Регламент применения биопрепаратов изложен в инструкциях по их использованию, которые необходимо строго соблюдать. Важно не только правильно использовать, но и правильно хранить биопрепараты. Желательно использовать только препараты в заводских упаковках и с коротким периодом хранения. Достаточно надежные биопрепараты для защиты от микоплазменной инфекции (желтухи) пока отсутствуют, однако подавление насекомых-переносчиков резко снижает вредоносность этого заболевания. Стратегия защиты от вирусной инфекции строится на использовании устойчивых генотипов, уничтожении насекомыхпереносчиков и растений-резерватов инфекции, жестком соблюдении санитарного режима. Санитарный режим предполагает ограничение свободного доступа в культивационные помещения посторонних лиц без спецодежды, строительство тамбуров на входе в сооружение с дезбарьером, комплексная дезинфекция при подготовке к эксплуатации и по ее окончании, оборудование систем вентиляции противомоскитными сетками. Такая система достаточно эффективна на культуре перца сладкого в весенних теплицах и позволяет получать экологически безопасную продукцию.

Использование новых высокопродуктивных гибридов перца сладкого с комплексной устойчивостью к болезням и освоение в производстве биологизированных технологий их выращивания в весенних теплицах, позволяет получать экологически безопасную продукцию для свежего потребления в межсезонный период.

В результате исследований были выявлены перспективные гибриды перца сладкого для весенних теплиц: $F_{1}$ Илона, $F_{1}$ Премьер, $F_{1}$ Корнелия, $F_{1}^{1}$ Валентина, $F_{1}$ Альянс, $F_{1}$ Байкал, $F_{1}$ Белогор, которые сочетают комплексную устойчивость к болезням с высокой продуктивностью и качеством продукции, а также пригодны для возделывания по биологизированным технологиям.

Для биологизации технологий выращивания перца сладкого в весенних теплицах на грунтах в культурообороты целесообразно включать промежуточные злаковые культуры на сидераты и применять биометод для защиты от вредителей и возбудителей болезней.
Библиографический список

1.Клименко Н.Н., Ховрин А.Н., Огнев В.В. Агрохолдинг «Поиск». Селекция здоровья и долголетия // Картофель и овощи. 2017. № 9. С. 8-10.

2.Пышная О.Н., Мамедов М.И., Пивоваров В.Ф. Селекция перца. М.: ВНИИССОК, 2012. 248 с.

3.Огнев В.В., Чернова Т.В., Гераськина Н.В. Исходный материал перца сладкого // Картофель и овощи. 2015. № 6. С. $14-15$.

4.Литвинов С.С., Нурметов Р.Д. Защищенный грунт стратегия развития // Картофель и овощи. 2013. № 10. C. 10 .

5.Огнев В.В., Чернова Т.В. Перец в пленочных теплицах на юге России // Картофель и овощи. 2014. № 2. С. $17-19$

6.Монахос Г.Ф. Селекция и семеноводство овощных культур в России на современном этапе // Вестник овощевода. 2012. № 1. С. 15-21.

7.Литвинов С.С. Методика полевого опыта в овощеводстве. М.: Россельхозакадемия, ВНИИО, 2011.648 с.

\section{Об авторах}

Огнев Валерий Владимирович, канд. с. - х. наук, доцент, директор Селекционно-семеноводческого центра «Ростовский» Агрохолдинга «Писк». E-mail: ognevvv@bk.ru (Контакт для переписки)

Чернова Татьяна Викторовна, селекционер, Селекционносеменоводческий центр «Ростовский» Агрохолдинга «Поиск»

Костенко Александр Николаевич, канд. с. - х. наук, региональный менеджер, Агрохолдинг «Поиск»

\section{Габибова Елена Николаевна,} канд. с. - х. наук, доцент, ФГБОУ ВО ДОНСКОЙ ГАУ

Мухортова Вера Константиновна, канд.с. - х. наук, доцент, ФГБОУ ВО ДОНСКОЙ ГАУ

Авдеенко Светлана Сергеевна, канд.с. - х. наук, доцент, ФГБОУ ВО Донской ГАУ

Environmentally safe production of sweet pepper in spring greenhouses V.V. Ognev, PhD, associate professor director of breeding and seed production centre Rostovsky, Poisk Agro Holding. E-mail: ognevvv@bk.ru (correspondence) T.V. Chernova, breeder of breeding and seed production centre Rostovsky, Poisk Agro Holding

A.N. Kostenko, $P h D$, head of promotion department, Poisk Agro Holding E.N. Gabibova, $P h D$, associate professor, Don State Agrarian University

V.K. Muchortova, $P h D$, associate professor, Don State Agrarian University S.S. Avdeenko, $P h D$, associate professor, Don State Agrarian University

Summary. The characteristic of sweet pepper hybrids for spring greenhouses and the technology of their cultivation using green manure and biological plant protection is given. It allows to obtain environmentally safe produce.

Keywords: sweet pepper, hybrid, spring greenhouse, biological protection, green manure 